\title{
PELAYANAN PURNA JUAL PRODUK SEPEDA MOTOR BERPENGARUH TERHADAP KEPUASAN NASABAH PADA PT. BPRS AL SALAAM CABANG DEPOK
}

\author{
Alfian Haikal ${ }^{1}$, Nizmah ${ }^{2}$, Bakti Toni Endaryono ${ }^{3}$ \\ ${ }^{1,2}$ Fakultas Ekonomi Universitas Surapati Jakarta \\ ${ }^{3}$ Program Studi Ekonomi Syariah IAI-N Laa Roiba Bogor \\ baktitoni@gmail.com
}

\begin{abstract}
PT BPRS Al Salaam Depok as sharia financing company in connection with the existence of banking business competition and tight financing, then try to improve service to nasanabah to remain faithful. Therefore, BPRS Al-Salaam tries to make customer/customer very trust to after sales service of motorcycle product and other syariah banking product. The coefficient of determination $\mathrm{Kd}=20.25 \%$ and and then the linear regression line is $\mathrm{Y}=19.25+0.43 \mathrm{X}$.

Keywords: after sales service and customer satisfaction.
\end{abstract}

\begin{abstract}
ABSTRAK
PT BPRS Al Salaam Depok selaku perusahaan pembiayaan syariah sehubungan dengan adanya persaingan usaha perbankan dan pembiayaan yang ketat, maka berusaha meningkatkan pelayanan kepada nasabah agar tetap setia. Oleh karena itu, BPRS Al Salaam berusaha agar pelanggan/nasabah sangat percaya kepada pelayanan purna jual produk sepeda motor dan produk perbankan syariah lainnya. Adaun dari hasil kuesioner yang disebarkan untuk penelitian, dan dianalisis, besarnya koefisien korelasi $r=0,45$, Koefisien determinasi $\mathrm{Kd}=20,25 \%$ dan dan kemudian garis linear regresinya adalah $\mathrm{Y}$ $=19,25+0,43 \mathrm{X}$.
\end{abstract}

\section{A. PENDAhuluan}

Perkembangan sistem keuangan syariah di Indonesia yang terdiri dari bank syariah, asuransi syariah, multifinance syariah, Penjaminan Syariah, pasar modal, dan Lembaga Keuangan Syariah lainnya merupakan suatu kesatuan yang saling berkaitan dalam mempengaruhi pertumbuhan industri keuangan syariah di Indonesia. Saling keterkaitan industri keuangan syariah ini dapat terlihat dari kondisi ketika bank syariah dengan pemain yang ada dan selalu bertambah serta kondisi pasar yang kompetitif akan mempengaruhi tingkat penghimpunan dana pihak ketiga (DPK) dan pembiayaan yang diberikan. Dari sisi DPK, ketika DPK yang banyak terhimpun dan membuat bank kelebihan likuiditas akan mempengaruhi pasar modal syariah, misalnya meningkatnya permintaan sukuk, juga management investasi syariah dan bank kustodian syariah. Dari sisi financing, ketika financing meningkat maka akan mempengaruhi lembaga penjamin pembiayaan dan multifinance syariah. Ketika pembiayaan dan multifinance syariah 
tumbuh maka juga akan mempengaruhi lembaga asuransi jiwa dan asuransi umum.

Sedangkan sejarah perkembangan bank syariah di Indonesia diawali dengan berdirinya Bank Muamalat Indonesia (BMI) pada 1 Mei 1992. Yang kemudian diikuti oleh lahirnya peraturan tentang perbankan yaitu, UU No. 7 Tahun 1992 tentang Perbankan Syariah yang mengakomodasi perbankan dengan prinsip bagi hasil baik bank umum maupun BPRS. ${ }^{1}$ Perkembangan selanjutnya adalah terbitnya UU No. 23 Tahun 1999 tentang Bank Indonesia (BI) yang mengakomodasi kebijakan moneter berdasarkan prinsip syariah dimana Bank Indonesia (BI) bertanggung jawab terhadap pengaturan dan pengawasan bank komersial termasuk bank syariah. ${ }^{2}$

Saat ini sebagian masyarakat Indonesia melihat bahwa nilai tambah bank syariah adalah lebih halal dan selamat, lebih menjanjikan untuk kebaikan akhirat, dan juga lebih berorientasi pada menolong antar sesama dibandingkan dengan bank konvensional. Hal tersebut memang benar, namun bank syariah memiliki keuntungan duniawi karena produk-produknya tidak kalah bersaing dengan bank-bank konvensional dan juga bagi hasil yang

1 Bank Perkreditan Rakyat. http://www. Google.co.id/\#hl=id\&q=pengertian+bank+perkre ditan+rakyat\&aq=f\&aqi=\&aql $=\quad \& o q \quad=\& g s-$ rfai $=\& f p=8$ fee 9696485 ef 279 . ditawarkan tidak kalah menguntungkan dibandingkan dengan bunga.

Dengan masih rendahnya pemahaman masyarakat akan pemahaman Islam apalagi masalah perbankan bahkan perekonomian secara lebih luas maka perbankan syariah harus terus berkembang dan memperbaiki kinerjanya. Dengan pesatnya pertumbuhan yang ditandai semakin banyaknya bank konvensional yang akhirnya mendirikan unit-unit syariah, ini membuktikan bahwa bank syariah memang mempunyai kompetensi yang tinggi. Perbankan syariah akan semakin tinggi lagi pertumbuhannya apabila masyarakat mempunyai permintaan dan antusias yang tinggi dikarenakan faktor peningkatan pemahaman dan pengetahuan tentang bank syariah, di samping faktor penyebab lainnya.

Tujuan dari pada penulisan ini secara umum adalah untuk mengetahui bagaimana sistematika penerapan sistem pelayanan purna jual untuk memberi kepuasan nasabah dan untuk mengetahui seberapa jauh tanggapan nasabah atas kepuasannya

2 BI, 2010. Statistik Perbankan Syariah (Islamic Banking Statistics).http://www.bi.go. id/web/id/Statistik/Statistik+Perbankan/Statistik+ Perbankan+Indonesia/spi_0510.htm. 
terhadap pelayanan purna jual sepeda motor. $^{3}$

\section{B. METODOLOGI}

Metode yang digunakan oleh penulis di sini mengumpulkan data dengan cara analisis deskriptif dan analisis kuantitatif. Analisis deskriptif, yaitu mengklasifikasikan data guna memecahkan masalah dengan mengumpulkan data, menyusun data, serta menginterpretasikannya berdasarkan kenyataan yang ada di lapangan. Analisis kuantitatif, yaitu mengolah data dengan cara menyaring informasi kejadian yang ada, kemudian menghubungkannya secara sistematis dengan menggunakan koefisien korelasi untuk membuktikan hipotesis.

Instrumen penelitian adalah alat yang digunakan untuk pengumpulan data. Instrumen penelitian di sini adalah wawancara, dokumentasi, cek, kuesioner. Dengan menggunakan skala likert katagori 5 yang berupa indikator nantinya terdiri dari 5 macam penilaian seperti berikut:

Tabel 1.1.

Jenis Jawaban

\begin{tabular}{|c|l|l|l|c|}
\hline $\begin{array}{c}\text { Pilihan } \\
\text { Jawaban }\end{array}$ & & Kategori Jawaban & & Skor \\
\hline A & Sangat penting & Sangat memuaskan & Sangat setuju & 5 \\
\hline B & Penting & Memuaskan & Setuju & 4 \\
\hline C & Cukup penting & Cukup memuaskan & Cukup setuju & 3 \\
\hline D & Tidak penting & Tidak memuaskan & Tidak setuju & 2 \\
\hline E & $\begin{array}{l}\text { Sangat tidak } \\
\text { penting }\end{array}$ & $\begin{array}{l}\text { Sangat tidak } \\
\text { memuaskan }\end{array}$ & $\begin{array}{l}\text { Sangat tidak } \\
\text { setuju }\end{array}$ & 1 \\
\hline
\end{tabular}

Rumus koefisien korelasi

menurut Sugiyono didalam

buku Metode Penelitian Bisnis: ${ }^{4}$

n. $(\Sigma X Y)-(\Sigma X) \cdot(\Sigma Y)$

$r=$

${ }^{3}$ Muhammad Syafii Antonio. (2001). Bank Syariah dari Teori ke Praktek. Jakarta: Gema Insani Press. hlm. 57.
${ }^{4}$ Sugiyono. (2006). Metode Penelitian Bisnis Kuantitatif Kualitatf dan R\&D. Bandung: Alfabet, hlm. 182. 


$$
\begin{aligned}
& {\left[\mathrm{n} /\left(\sum \mathrm{X}^{2}\right)-(\Sigma X)^{2}\right]\left[n\left(\Sigma Y^{2}\right)-(\right.} \\
& \left.\Sigma Y)^{2}\right]
\end{aligned}
$$

Dimana $\mathrm{r}=$ Koefisien Korelasi

Adapun pedoman interpretasi dari koefisien tersebut adalah:

Tabel 1.2

Pedoman untuk Memberikan Interpretasi Koefisien Korelasi

\begin{tabular}{|c|l|}
\hline Interpretasi Koefisien korelasi & \multicolumn{1}{|c|}{ Tingkat Hubungan } \\
\hline $0.10-0.19$ & Sangat Lemah \\
\hline $0.20-0.39$ & Lemah \\
\hline $0.40-0.59$ & Sedang \\
\hline $0.60-0.79$ & Kuat \\
\hline $0.80-1.00$ & Sangat Kuat \\
\hline
\end{tabular}

\section{HASIL DAN PEMBAHASAN}

Konsumen yang dimaksud adalah nasabah di bank syariah. Nasabah merupakan konsumen yang mempercayakan harta yang dimilikinya kepada pihak bank untuk dijaga dan dikelola dengan baik. Nasabah juga dapat melakukan kerjasama dengan pihak bank untuk melakukan suatu usaha halal dan baik. Nasabah juga dapat bertransaksi jual beli dengan pihak bank syariah itu sendiri. Oleh karena itu, yang dimaksud konsumen dalam penelitian ini adalah nasabah maupun masyarakat lainnya yang tertarik untuk menjadi nasabah dan bertransaksi dengan bank syariah.

Nasabah pada bank syariah dibagi menjadi tiga, yaitu nasabah tabungan, nasabah deposito, dan nasabah pembiayaan. Nasabah tabungan adalah nasabah yang menginvestasikan dananya di bank syariah dalam bentuk tabungan. Nasabah deposito adalah nasabah yang menginvestasikan dananya di bank syariah dalam bentuk deposito. Dana dari nasabah tabungan dan deposito ini kemudian digunakan oleh bank syariah sebagai sumber dana untuk dikelola secara profesional, amanah, dan transparan. Sedangkan nasabah pembiayaan adalah nasabah yang bermitra dengan bank syariah, untuk melakukan usaha yang halal dan prospektif, sehingga sumber bagi hasil pada bank syariah itu berasal dari usaha yang dilakukan oleh nasabah pembiayaan. 


\section{Ad-Deenar Jurnal Ekonomi dan Bisnis Islam}

Definisi pelayanan menurut Philip Kotler yang dikutip oleh Djaslim Saladin dalam bukunya ${ }^{5}$ adalah sebagai berikut: ${ }^{6}$

"A service is any act or performance that one party can offer to another that is essentially intangible and does not result in the ownership of anything. It's production may or may not be tied to physical product."

Artinya: "Pelayanan adalah setiap tindakan atau kinerja yang ditawarkan oleh suatu pihak lain dan pada dasarnya tidak berwujud, serta tidak menghasilkan kepemilikan atas sesuatu. Kegiatan ini mungkin atau tidak mungkin berhubungan dengan produk fisik".

Adanya kepuasan nasabah dapat memberikan beberapa manfaat, di antaranya menurut Fandy Tjiptono (1994: 9) dikutip kembali oleh Fandy Tjiptono dan Anastasia Diana mengatakan bahwa Manfaat kepuasaan konsumen/nasabah di antaranya sebagai berikut: ${ }^{7}$

1. Hubungan antara instansi (BPRS Al Salaam Depok) dan para nasabah menjadi harmonis.

2. Memberikan dasar yang baik bagi kedua belah pihak.

5 Djaslim Saladin. (2006). Manajemen Pemasaran, Analisis, Perencanaan, Pelaksanaan, dan Pengendalian. Jakarta: Salemba Empat. hlm. 135)
3. Dapat mendorong terciptanya loyalitas nasabah.

4. Membentuk suatu rekomendasi dari mulut ke mulut (word-of-mouth) yang menguntungkan bagi BPRS Al Salaam Depok.

5. Reputasi BPRS Al Salaam Depok menjadi baik di mata nasabah.

Istilah pembiayaan pada intinya berarti I Believe, I Trust (saya percaya atau saya menaruh kepercayaan). Dengan demikian pengertian pembiayaan adalah:

1. Penyerahan nilai ekonomi sekarang atas kepercayaan dengan harapan mendapatkan kembali suatu ekonomi yang sama di kemudian hari.

2. Suatu tindakan atas dasar perjanjian yang dalam perjanjian tersebut terdapat jasa dan balas jas (prestasi dan kontra prestasi) yang keduanya dipisahkan oleh unsur waktu.

3. Pembiayaan adalah suatu hak, dengan hak mana seseorang dapat menggunakannya untuk tujuan tertentu dalam batas waktu tertentuu dan atas pertimbangan tertentu pula.

6 Philip Kotler. (2004). Manajemen Pemasaran2. Edisi Millenium, Jakarta: PT Ikrar Mandiri. hlm. 428.

7 Anastasia Diana. (1995). Total Quality Management. Malang: Graha Ilmu. hlm. 102. 
Adapun hasil dari kuesioner yang disebarkan, dan setelah dianalisis, besarnya koefisien korelasi $\mathrm{r}=0,45$, koefisien determinasi $\mathrm{Kd}=20,25 \%$ dan dan kemudian garis linear regresinya adalah $\mathrm{Y}=19,25+0,43 \mathrm{X}$.

\section{KESIMPULAN}

Hubungan antara peranan pelayanan dengan kepuasan nasabah BPRS Al Salaam dapat dilihat dari besarnya angka indeks "r" (korelasi Product Moment dari Person) sebesar 0,45 dengan interpretasi nilai korelasi tergolong sedang. Kuat lemahnya peranan pelayanan memberikan kontribusi terhadap besar kecilnya kemungkinan

\section{DAFTAR PUSTAKA}

Djaslim Saladin. (2006). Manajemen Pemasaran, Analisis, Perencanaan, Pelaksanaan, dan Pengendalian. Jakarta: Salemba Empat.

Philip Kotler. (2004). Manajemen Pemasaran2. Edisi Millenium, Jakarta: PT Ikrar Mandiri.

Antonio, M.S. (2001). Bank Syariah dari Teori ke Praktek. Jakarta: Gema Insani Press. untuk mencapai kepuasan nasabah yang lebih tinggi; artinya bahwa semakin baik pelayanan, maka semakin besar pula kemungkinan untuk mencapai kepuasan nasabah yang tinggi.

Kontribusi pelayanan terhadap kepuasan pelanggan adalah sebesar 2025 $\%$, sedangkan sisanya $79,75 \%$ lainnya ditentukan faktor-faktor lain.

Dari hasil Analisis Koefisien Regresi $Y=19,25+0,43 X$, semakin besar nilai $X$ maka menjadikan semakin bertambah besar pula nilai $\mathrm{Y}$ artinya bila pelayanan semakin baik maka kepuasan nasabah akan menjadi semakin meningkat pula.

Anastasia Diana. (1995). Total Quality Management. Malang: Graha Ilmu.

Sugiyono. (2006). Metode Penelitian Bisnis Kuantitatif Kualitatf dan $R \& D$. Bandung: Alfabet.

Bank Perkreditan Rakyat. http://www.

Google.co.id/\#hl=id\&q=pengertian + bank+perkreditan+rakyat\&aq $=\mathrm{f} \&$ aqi $=\& a q l=\quad \& o q=\& g s r f a i=\& f p$ $=8$ fee 9696485 ef 279 .

BI, 2010. Statistik Perbankan Syariah (Islamic Banking Statistics). http://www.bi.go.id/web/id/Statistik/St atistik+Perbankan/Statistik+Perban kan+Indonesia/spi_0510.htm. 